\title{
Antibiotic resistance in Swiss nursing homes: analysis of National Surveillance Data over an 11-year period between 2007 and 2017
}

Philipp Kohler ${ }^{1 *} \mathbb{D}$, Rosamaria Fulchini ${ }^{1}$, Werner C. Albrich ${ }^{1}$, Adrian Egli ${ }^{2,3}$, Carlo Balmelli ${ }^{4}$, Stephan Harbarth ${ }^{5}$, Delphine Héquet ${ }^{6}$, Christian R. Kahlert ${ }^{1,7}$, Stefan P. Kuster $^{8}$, Christiane Petignat ${ }^{6}$, Matthias Schlegel ${ }^{1}$ and Andreas Kronenberg ${ }^{9,10}$

\begin{abstract}
Background: We evaluated data from isolates of nursing home $(\mathrm{NH})$ patients sent to the Swiss centre for antibiotic resistance (ANRESIS). We focussed on carbapenem-resistance (CR) among Gram-negative pathogens, extendedspectrum cephalosporin-resistant (ESC-R) Escherichia coli/Klebsiella pneumoniae, methicillin-resistant Staphylococcus aureus (MRSA), and glycopeptide-resistant enterococci (GRE).

Methods: NH patient isolates from 01/2007 to 10/2017 were extracted. Temporal trends in resistance were described and risk factors associated with ESC-R and MRSA were assessed. For every administrative subdivision in Switzerland (i.e. canton), we calculated a coverage rate, defined as number of beds of governmentally-supported nursing homes, which sent $\geq 1$ isolate in each 2014, 2015, and 2016, divided by the total number of supported beds.

Results: We identified 16'804 samples from 9'940 patients. A majority of samples (12'040; 71.6\%) originated from the French/Italian speaking part of Switzerland. ESC-R E. coli increased from 5\% (16/299) in 2007 to 22\% (191/884) in $2017(P<0.01)$, whereas MRSA decreased from 34\% (35/102) to 26\% $(21 / 81)(P<0.01)$. Provenience from the German (vs. French/Italian) speaking part of Switzerland was associated with decreased risk for ESC-R (OR 0.5, 95\% Cl 0.4-0.7) and for MRSA (OR 0.1, 95\% Cl 0.1-0.2). CR among Pseudomonas aeruginosa was 10\% (105/1096) and showed an increasing trend over time; CR among Enterobacteriaceae (37/12'423, 0.3\%) and GRE (5/1'273, 0.4\%) were uncommon. Overall coverage rate was $9 \%$ (range 0-58\% per canton). There was a significant difference between the French/Italian (median 13\%, interquartile range [IQR] 4-43\%) and the German speaking cantons (median 0\%, IQR 0-5\%) $(P=0.02)$.

Conclusions: ESC-R among E. coli is emerging in Swiss NHs, whereas MRSA show a declining trend over time. A minority of NHs are represented in ANRESIS, with a preponderance of institutions from the French/Italian speaking regions. Efforts should be undertaken to improve resistance surveillance in this high-risk setting.
\end{abstract}

Keywords: Antibiotic resistance, Long-term care facility, Nursing homes, Extended-spectrum cephalosporin resistance, Methicillin-resistant Staphylococcus aureus, Switzerland

\footnotetext{
* Correspondence: philipp.kohler@kssg.ch

${ }^{1}$ Division of Infectious Diseases and Hospital Epidemiology, Kantonsspital St.

Gallen, St. Gallen, Switzerland

Full list of author information is available at the end of the article
}

(c) The Author(s). 2018 Open Access This article is distributed under the terms of the Creative Commons Attribution 4.0 International License (http://creativecommons.org/licenses/by/4.0/), which permits unrestricted use, distribution, and reproduction in any medium, provided you give appropriate credit to the original author(s) and the source, provide a link to the Creative Commons license, and indicate if changes were made. The Creative Commons Public Domain Dedication waiver (http://creativecommons.org/publicdomain/zero/1.0/) applies to the data made available in this article, unless otherwise stated. 


\section{Background}

Long-term care facilities (LTCF) have been recognized as an important reservoir for antibiotic resistant pathogens [1-3]. In a recent point-prevalence study from four different LTCF in Italy, the prevalence of extended-spectrum beta-lactamase (ESBL)-carriage was $57 \%$ and of methicillin-resistant Staphylococcus aureus (MRSA) 17\% [4]. Also in Italy, the prevalence of carbapenemase-producing Enterobacteriaceae (CPE) - one of the most concerning antibiotic resistance threats - ranged from 1 to 6.3\% [5]. Residence in an LTCF has been shown to be a risk factor for carriage of MRSA and glycopeptide-resistant enterococci (GRE) [6, 7]. Risk factors for resistant pathogens among nursing home $(\mathrm{NH})$ residents include previous antibiotic treatment, invasive devices, age, open wounds, sharing a room with a colonized patient, bedriddenness, or high degree of disability $[2,4,5,8,9]$.

In Switzerland, studies on antibiotic resistance from NHs or other LTCFs have mostly focussed on MRSA and have almost exclusively been generated in the Western part of the country [10-13]. Previously published national surveillance data on MRSA and extended-spectrum cephalosporin resistant (ESC-R) Enterobacteriaceae from Switzerland have not included data from LTCF $[14,15]$. In light of the alarming trends in antibiotic resistance from LTCF in neighboring countries, we aimed to assess temporal trends in the prevalence of antibiotic resistant isolates from patients in Swiss NHs and to identify risk factors associated with resistance.

\section{Methods}

\section{Setting}

This observational laboratory-based study was conducted using the database from the Swiss antimicrobial resistance surveillance network (ANRESIS) available since 2004 [16]. This database provides antibiotic resistance data for all routinely collected microbiological samples from 20 clinical microbiology laboratories, distributed all over Switzerland and representing at least $70 \%$ of annual hospitalization days and $30 \%$ of all Swiss general practitioners. For this analysis, we included all isolates sent to ANRESIS from Swiss NHs.

Antimicrobial susceptibility testing was performed at local laboratories according to Clinical and Laboratory Standards Institute (CLSI) or European Committee on Antimicrobial Susceptibility Testing (EUCAST) guidelines [17, 18]. Most of the participating laboratories switched from CLSI to EUCAST breakpoints between 2011 and 2013. All laboratories are participating in at least one external quality program out of the National External Quality Assessment Service or the Swiss quality control program from the Institute for Medical Microbiology, University of Zurich [19, 20].

\section{Inclusion criteria and definitions}

We extracted resistance data for all Enterobacteriaceae, Pseudomonas aeruginosa, Acinetobacter spp., Staphylococcus aureus and Enterococcus faecium/faecalis which were sent to ANRESIS between January 2007 until October 2017 with the patient label "long-term care" and which originated from Swiss NHs. These pathogens represent $81 \%$ of $\mathrm{NH}$ isolates sent to ANRESIS during this time period. Although data were anonymous, every patient possesses a unique identity number within their institution, which was used to exclude repeat isolates (i.e. same pathogen and resistance profile) from the same patient in a specific calendar year. Each of the 26 administrative subdivisions in Switzerland (i.e. cantons) was assigned to either the French/Italian (cantons of Fribourg, Geneva, Jura, Ticino, Valais and Vaud), or the German speaking part (all other cantons). Based on the name of the institution linked to the isolate we distinguished the following types of institutions: i) governmentally supported NHs according to publicly available lists issued by the Federal Office of Public Health (FOPH) [21]; and ii) not governmentally supported NHs.

For Enterobacteriaceae, Pseudomonas aeruginosa and Acinetobacter spp., carbapenem-resistance (CR) was studied. For Escherichia coli and Klebsiella pneumoniae, ESC-R as well as co-resistances to quinolones, aminoglycosides, nitrofurantoin, and fosfomycin were evaluated. Oxacillin- or cefoxitin-resistance among Staphylococcus aureus was used as a proxy for methicillin-resistant $S$. aureus (MRSA). Glycopeptide-resistant Enterococcus faecalis/faecium (GRE) were also studied. Resistance to a particular substance was defined as either intermediate or resistant susceptibility test according to the individual laboratories. Group resistance (e.g. glycopeptide, carbapenem, aminoglycoside or quinolone resistance) was defined as resistance or intermediate susceptibility to at least one antibiotic of the respective group, ESC-R was defined as resistance or intermediate susceptibility to at least one antibiotic tested out of 3rd or 4th generation cephalosporins.

\section{Calculation of coverage rate}

For every canton, we estimated the coverage rate of governmentally supported NHs sending microbiology isolates to ANRESIS. This was achieved by dividing the number of beds represented by institutions in the dataset who sent at least one isolate to ANRESIS in 2014, 2015, and 2016 by the total number of beds. The number of supported beds was collected from publicly available lists of the FOPH for the year 2016 [21, 22].

\section{Data analysis and statistics}

Categorical variables were reported as frequencies and proportions, continuous variables as median with interquartile 
range (IQR). For dichotomous variables, Chi-square or Fisher-exact tests were used, as appropriate. For comparison of coverage rates between geographic regions, the Mann-Whitney-U was used. For each type of resistance, the proportion of pathogens with the resistance trait (as \% of the total number of isolates reported and tested for the respective key antibiotic) was analysed over time. Linear regression analysis was used to estimate the association between resistance (independent variable) and year of surveillance (dependent variable).

For ESC-R and MRSA, univariable and multivariable logistic regression analysis with generalized estimating equation (GEE) were performed to assess factors independently associated with resistance. The following co-variables were assessed: Patient age group (i.e. $<70$, $70-85,>85$ years), sex, geographical region (i.e. French/ Italian, German), and site of sample collection (i.e. urogenital, skin, respiratory, other). Co-variables were entered into multivariable analysis in case of a $P$ value $<0.1$ in univariable analysis. Two-sided $P$ values $\leq 0.05$ were considered statistically significant. SAS Studio was used for all statistical analyses.

\section{Sensitivity analysis}

To eliminate potential selection bias, a sensitivity analysis was performed assessing resistance time trends exclusively for NHs which sent microbiological isolates every year between 2007 and 2017 (only for ESC-R and MRSA, as the sample sizes for the other pathogens were too small).

\section{Results}

\section{Data sources}

After removal of duplicates, we identified 19'189 tested pathogens from 16'804 samples and 9'940 patients. Of the samples, 14'663 (87.3\%) were from governmentally funded NHs and 2'141 (12.7\%) from non-funded NHs. A majority of samples $\left(12^{\prime} 040 ; 71.6 \%\right)$ originated from the French/Italian and 4'764 (28.4\%) from the German speaking part of Switzerland.

\section{ESC-R for E. Coli and K. pneumoniae}

We identified 8'607 E. coli and 1'825 K. pneumoniae isolates, mostly from the urinary tract $(97 \%$ of $E$. coli and $94 \%$ of $K$. pneumoniae). ESC-R was more common among E. coli (14.1\%) compared to $K$. pneumoniae (7.0\%). From 2007 to 2017, ESC-R E. coli increased from $5.4 \%(16 / 299)$ to $21.6 \%(191 / 884)(P<0.0001)$ (Fig. 1a). A similar but less pronounced increase from 1.6 to $7.8 \%$ was observed for ESC-R K. pneumoniae $(P<0.0001)$. In multivariable analysis, isolates originating from the German speaking part of Switzerland (vs. French/Italian; OR 0.5, 95\% CI 0.4-0.7) were less likely, and those from men (vs. women; OR 1.6, 95\% CI 1.2-2.1) more likely to exhibit ESC-R (Table 1). Co-resistances were more frequent in the ESC-R group, for both $E$. coli and $K$. pneumoniae. For ESC-R E. coli, resistance to fluoroquinolones was $75 \%$, whereas resistance to aminoglycosides, nitrofurantoin and fosfomycin were 25.7, 8.8 and $6.8 \%$, respectively (Fig. 2).

\section{Carbapenem-resistance (CR)}

Among Enterobacteriaceae, 37 of 12'423 tested isolates $(0.3 \%)$ were resistant to carbapenems. CR was more common among patients less than 70 years of age $(P=$ $0.01)$ and those from the French/Italian speaking regions $(P=0.01)$; no time trend was observed $(P=0.14)$. Among P. aeruginosa, 105 of 1'096 isolates (9.6\%) showed CR, with an increasing trend from 2007 (2\%) to 2016 (8\%) $(P=0.0001)$. Non-urogenital isolates (thereof $68 \%$ skin and $25 \%$ respiratory isolates) more frequently exhibited CR (12.3\%) than urogenital samples (8.4\%, $P=0.04$ ). Among 83 tested Acinetobacter spp. isolates, none exhibited CR. Additional file 1: Table S1 gives an overview on the isolates included in this analysis.

\section{Methicillin-resistant Staphylococcus aureus}

Among 1'482 isolates of S. aureus, 556 (37.5\%) were resistant to methicillin. Prevalence decreased over time from $34.3 \%(35 / 102)$ in 2007 to $25.9 \%(21 / 81)$ in 2017 $(P=0.004)$ (Fig. 1a). Geographical provenance was the only factor associated with methicillin-resistance in multivariable analysis, with isolates from the German part being less commonly resistant than those from French/ Italian speaking parts of Switzerland (OR 0.1, 95\% CI $0.1-0.2, P<0.0001$ ) (Table 2).

\section{Glycopeptide-resistant enterococci}

GR among enterococci was uncommon (5/1'273; 0.4\%). Due to the small number of resistant isolates, no further analyses were performed. Additional file 1: Table S1 gives an overview on the isolates included in this analysis.

\section{Sensitivity analysis}

Considering only institutions participating in ANRESIS from 2007 throughout to 2017, the same time trends could be observed for ESC-R (15 institutions, 1'555 isolates) with resistance increasing from $4.2 \%$ in 2007 to $21.7 \%$ in $2017(P<0.0001)$. For MRSA (14 institutions, 201 isolates), the high proportion of resistance persisted from $2007(42.4 \%)$ to $2017(60 \%)(P=0.61)$.

\section{Coverage of governmentally supported institutions}

Considering 11'584 samples from governmentally funded NHs which sent samples throughout 2014 to 2016, the national coverage rate of supported $\mathrm{NH}$ beds was $9 \%$. Whereas some cantons did not provide any isolates to ANRESIS, others had coverage rates of up to $58 \%$, again with a significant difference between the 

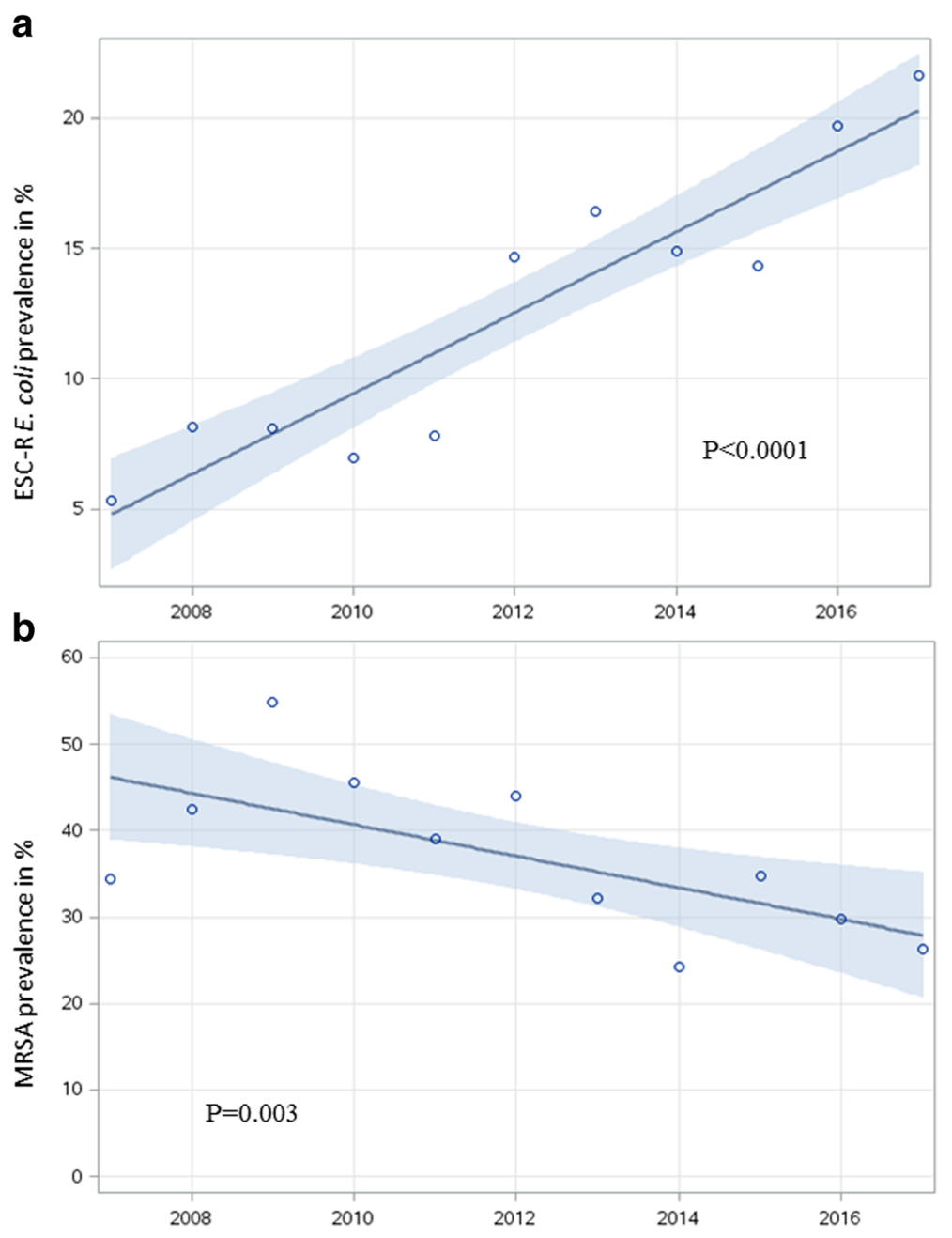

Fig. 1 Resistance trends (in \%, y-axis) of ESC-R Escherichia coli (a) and of methicillin-resistant Staphylococcus aureus (b) in Swiss nursing homes between 2007 and 2017 using a linear regression model (including 95\% confidence interval in light blue)

French/Italian (median 13\%, IQR 4-43\%) and the German (median 0\%, IQR 0-5\%) speaking part of the country $(P=0.02)$. Additional file 1: Figure $S 1$ shows the coverage rate for every canton.

\section{Discussion}

In this analysis of national resistance data from Swiss $\mathrm{NHs}$, we show that ESC-R have been clearly increasing between 2007 and 2017 reaching 22\% among E. coli isolates, whereas the proportion of MRSA among $S$. aureus isolates is declining. The nationwide collection of $\mathrm{NH}$ isolates and the inclusion of data over more than a decade are notable strengths of this study and increase its validity and significance.

The analysis of the available resistance data shows a significant increase of ESC-R among E. coli and $K$. pneumoniae. These findings mirror the increase of ESC-R observed in an ANRESIS analysis of inpatient and outpatient isolates from Swiss acute care institutions [15]. According to the ANRESIS database, the proportion of ESC-R among invasive $E$. coli acute care isolates for the year 2016 was $9 \%$, compared to $18 \%$ in our data [23]. This supports the notion of NHs being a high-risk setting for ESBL-producing pathogens. In contrast to the study by Kronenberg et al., where isolates from the German part of Switzerland exhibited slightly more frequently ESC-R, we found - on the contrary - a significantly higher resistance rate among isolates originating from French/Italian speaking regions [15]. Indeed, particularly for resistant Gram-negative pathogens, the countries bordering Switzerland in the South (Italy) and in the West (France) have reported a high ESBL prevalence of 58\% among $\mathrm{NH}$ residents and $28 \%$ among patients on geriatric wards, respectively [4, 24]. In Germany and Austria, somewhat lower ESBL carriage rates of 18 and $13 \%$ have been reported from these settings $[25,26]$. In our study, male 
Table 1 Patient characteristics and univariable and multivariable logistic regression using generalized estimating equation for evaluation of risk factors for ESC-R in patients with Escherichia coli and Klebsiella pneumoniae isolates from Swiss NHs between 2007 and 2016

\begin{tabular}{|c|c|c|c|c|c|c|c|}
\hline & \multirow{2}{*}{$\begin{array}{l}\text { ESC-S } \\
n=9^{\prime} 093\end{array}$} & \multicolumn{2}{|l|}{ ESC-R } & \multicolumn{2}{|l|}{ Univariable } & \multicolumn{2}{|l|}{ Multivariable } \\
\hline & & $n=1 ' 339$ & Row $\%^{\mathrm{a}}$ & $\overline{\mathrm{OR}}(95 \% \mathrm{Cl})$ & $P$ value & $\overline{\mathrm{OR}}(95 \% \mathrm{Cl})$ & $P$ value \\
\hline Sex & & & & & 0.03 & & 0.003 \\
\hline Female & 7'436 & $1 ' 063$ & 12.5 & ref. & & ref. & \\
\hline Male & $1 ' 657$ & 276 & 14.3 & $1.4(1.0-1.9)$ & & $1.6(1.2-2.1)$ & \\
\hline \multicolumn{8}{|l|}{ Age in years } \\
\hline$<70$ & 713 & 110 & 13.4 & ref. & & - & \\
\hline $70-85$ & $5^{\prime} 479$ & 799 & 12.7 & $0.9(0.7-1.2)$ & 0.60 & & \\
\hline$>85$ & 2'901 & 430 & 12.9 & $1.0(0.8-1.2)$ & 0.74 & & \\
\hline \multicolumn{8}{|l|}{ Region } \\
\hline French/Italian speaking & $6^{\prime} 407$ & $1 ' 037$ & 13.9 & ref. & & ref. & \\
\hline German speaking & $2^{\prime} 686$ & 302 & 10.1 & $0.5(0.4-0.7)$ & $<.0001$ & $0.5(0.4-0.7)$ & $<.0001$ \\
\hline \multicolumn{8}{|l|}{ Site } \\
\hline Urogenital & $8^{\prime} 788$ & $1 ' 286$ & 12.8 & ref. & & - & \\
\hline Other & 305 & 53 & 14.8 & $1.4(0.7-2.5)$ & 0.34 & & \\
\hline \multicolumn{8}{|l|}{ Species } \\
\hline E. coli & 7'396 & $1 ' 211$ & 14.1 & ref. & & ref. & \\
\hline K. pneumoniae & $1 ' 697$ & 128 & 7.0 & $0.2(0.1-0.3)$ & $<.0001$ & $0.2(0.1-0.3)$ & $<.0001$ \\
\hline
\end{tabular}

Abbreviations: ESC- $R$ Extended-spectrum beta-lactam resistant, ESC-S Extended-spectrum beta-lactam susceptible, $N H$ Nursing Home, OR Odds Ratio, $C$ Confidence Interval, ref Reference

Significant $P$ values are in bold and non-significant ones $(P \geq 0.05)$ are not in bold ${ }^{a}$ ESC-R/(ESC-S + ESC-R)

sex was clearly associated with ESC-R, which has also been described for patients in Switzerland not residing in $\mathrm{NHs}$ [15]. Although several other studies have documented an association of male sex with carriage of or infection with ESBL-producing organisms [27-29], others found female sex to be associated with ESBL-carriage or infection [30-32]. It has been suggested that these conflicting findings might be due to differences in antibiotic prescribing practices for women with uncomplicated cystitis [27]. Interestingly, the proportion of ESC-R E. coli with co-resistance to fluoroquinolones was high at $75 \%$ in our study. Whether this high proportion is due to the dissemination of the frequently fluroroquinolone-resistant ST131 E. coli clone in Swiss NHs (as shown for other countries) should be further evaluated [33-35]. Based on our resistance data and in accordance with national antibiotic treatment guidelines, nitrofurantoin and fosfomycin remain reasonable options for the empirical treatment of $\mathrm{NH}$ patients, at least for uncomplicated urinary tract infections [36].

We found the proportion of MRSA among S. aureus isolates to be declining between 2007 and 2017. This is in line with national acute care resistance data, but also with two point-prevalence studies performed in 2010/11 and 2015 among residents of $\mathrm{NH}$ in the canton of Vaud
$[10,13,14]$. In addition, samples from the German speaking part of Switzerland less commonly exhibited methicillin-resistance than those from French/Italian speaking parts, which also has been shown for the Swiss acute care setting [14]. Nevertheless, these data - and particularly the high resistance rates of over $50 \%$ in 2009 - should be interpreted with caution because i) the absolute number of $S$. aureus isolates was relatively small $(N$ $=1^{\prime} 482$ ), and ii) the decreasing trend over time could not be confirmed in the sensitivity analysis.

$\mathrm{CR}$ among $P$. aeruginosa from $\mathrm{NH}$ residents is increasing in all geographic regions in Switzerland. Potential explanations include the increasing use of carbapenems and/or the change from CLSI to EUCAST breakpoints, which has been shown to lead to decreased susceptibility rates, in particular for $P$. aeruginosa tested for carbapenems [37-39]. The proportion of CR among Enterobacteriaceae and Acinetobacter spp. as well as glycopeptide resistance among enterococci is negligible in Swiss NHs. Nevertheless, especially for CR among Enterobacteriaceae, regular surveillance is indicated in light of their emergence in geographically close regions such as Northern Italy, where LTCF are known high-risk settings for these pathogens.

Only $9 \%$ of governmentally-supported $\mathrm{NH}$ beds in Switzerland are represented in ANRESIS and from 


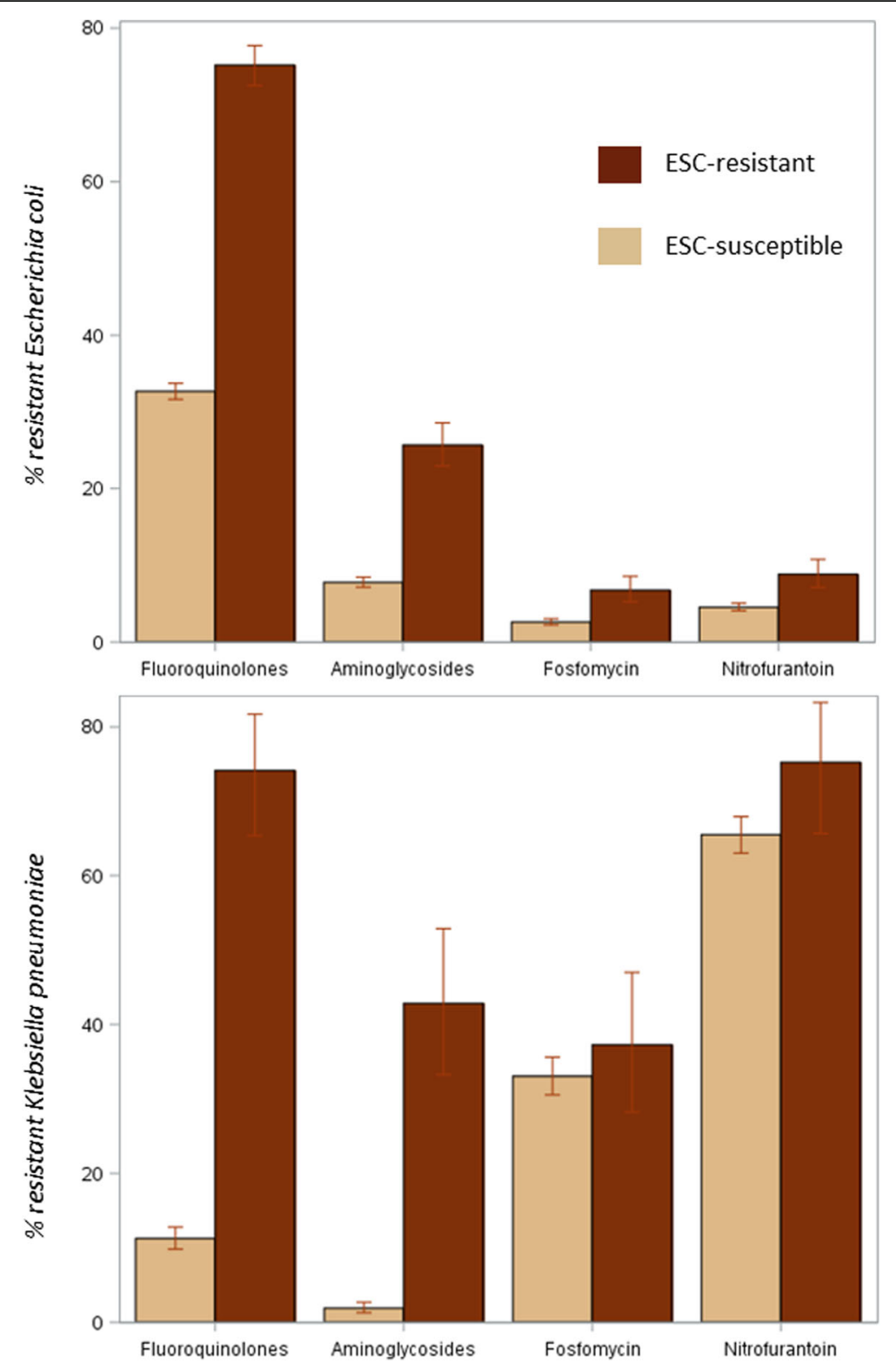

Fig. 2 Co-resistances of Escherichia coli and Klebsiella pneumoniae isolates from Swiss nursing home residents between 2007 and 2016 , by resistance to extended-spectrum cephalosporins (ESC), including 95\% confidence intervals

many cantons in the German speaking part of Switzerland, LTCF isolates are lacking completely. We can only speculate on the reasons for these gaps in the reporting system. One potential reason is that $\mathrm{NH}$ residents are often treated by their family physicians, and therefore the samples are not attributed to the institution, but to general physicians. By only including samples which could be unambiguously ascribed to NHs, we also decreased the number of samples and the statistical power of our analysis. However, the credibility and validity of our results are strengthened through this approach.
Our study has several limitations. First, the overrepresentation of the French/Italian speaking part of the country hampers the generalizability of our analysis. Still, we believe that the available data are of interest to public health authorities, clinical microbiologists, hospital epidemiologists, and also to clinicians in care of $\mathrm{NH}$ patients. Second, comparability of laboratory data across different institutions over more than a decade can be debated. As mentioned above, several laboratories have switched from CLSI to EUCAST breakpoints during the observed time period. Also, we cannot exclude inconsistencies in testing for particular antibiotic 
Table 2 Patient characteristics and results of univariable and multivariable logistic regression using generalized estimating equation for risk factors for methicillin-resistance in patients with Staphylococcus aureus isolates from Swiss nursing homes between 2007 and 2017

\begin{tabular}{|c|c|c|c|c|c|c|c|}
\hline & \multirow{2}{*}{$\begin{array}{l}\text { MSSA } \\
n=926\end{array}$} & \multicolumn{2}{|l|}{ MRSA } & \multicolumn{2}{|l|}{ Univariable } & \multicolumn{2}{|l|}{ Multivariable } \\
\hline & & $n=556$ & Row $\%^{a}$ & $\mathrm{OR}(95 \% \mathrm{Cl})$ & $P$ value & $\mathrm{OR}(95 \% \mathrm{Cl})$ & $P$ value \\
\hline \multicolumn{8}{|l|}{ Sex } \\
\hline Female & 542 & 298 & 35.5 & ref. & & ref. & \\
\hline Male & 384 & 258 & 40.2 & $1.4(0.9-2.2)$ & 0.11 & $1.6(1.0-2.5)$ & 0.06 \\
\hline \multicolumn{8}{|l|}{ Age in years } \\
\hline$<70$ & 133 & 57 & 30.0 & ref. & & ref. & \\
\hline $70-85$ & 563 & 361 & 39.1 & $1.5(1.1-2.2)$ & 0.02 & $1.3(0.9-1.9)$ & 0.13 \\
\hline$>85$ & 230 & 138 & 37.5 & $1.5(1.0-2.2)$ & 0.04 & $1.3(0.8-1.9)$ & 0.27 \\
\hline \multicolumn{8}{|l|}{ Region } \\
\hline French/Italian speaking & 697 & 498 & 41.7 & ref. & & ref. & \\
\hline German speaking & 229 & 58 & 20.2 & $0.1(0.1-0.2)$ & $<0.0001$ & $0.1(0.1-0.2)$ & $<0.0001$ \\
\hline \multicolumn{8}{|l|}{ Sampling site } \\
\hline Urogenital & 259 & 174 & 40.2 & ref. & & ref. & \\
\hline Skin & 492 & 294 & 37.4 & $0.9(0.7-1.2)$ & 0.44 & $0.9(0.7-1.1)$ & 0.20 \\
\hline Other & 175 & 88 & 33.5 & $0.8(0.5-1.1)$ & 0.09 & $0.7(0.5-1.0)$ & 0.06 \\
\hline
\end{tabular}

Abbreviations: MSSA Methicillin-susceptible Staphylococcus aureus, MRSA Methicillin-resistant Staphylococcus aureus, OR Odds Ratio, CI Confidence Interval Significant $P$ values are in bold and non-significant ones $(P \geq 0.05)$ are not in bold ${ }^{\mathrm{a}} \mathrm{ESC}-\mathrm{R} /(\mathrm{ESC}-\mathrm{S}+\mathrm{ESC}-\mathrm{R})$

substances such as fosfomycin, which requires the determination of the minimal inhibitory concentration in the presence of glucose-6-phosphate. Third, we cannot fully exclude the possibility that collection practices changed during the observed time period or between geographical regions in Switzerland, which might have confounded our results. Fourth, it remains debatable to what extent ESC-R can be used as a proxy for ESBL-production. However, in the 2016 antibiotic resistance report of the European Centre for Disease Prevention and Control, 89\% of ESC-R E. coli were ESBL-producers [40]. Fifth, our approach of calculating a coverage rate for every canton can be discussed. Because the number of samples sent per institution was not considered in the calculation, large institutions sending few samples to ANRESIS will be overrepresented compared to small institutions sending many samples. Sixth, because certain pathogens such as streptococci are not included in our analysis, the coverage rate might be slightly underestimated. However, we found that the isolates in our study represent $81 \%$ of all $\mathrm{NH}$ isolates, which allows to reasonably estimate the coverage rate.

\section{Conclusions}

The prevalence of ESC-R E. coli and K. pneumoniae among Swiss NHs has clearly been increasing over the last decade. In this analysis of mostly urinary samples, nitrofurantoin and fosfomycin retained high susceptibility rates against $E$. coli, even for ESC-R isolates. The proportion of MRSA among $S$. aureus seems to be declining. Efforts should be undertaken to increase the coverage of NHs samples in the national resistance database ANRESIS, especially in the German speaking parts of Switzerland.

\section{Additional file}

Additional file 1: Table S1. Number of isolates included in the analysis by pathogen vs. sex, age group, site of detection and geographical region. Figure S1. Total and in ANRESIS represented proportion (i.e. coverage rate) of governmentally supported nursing home beds per canton. (DOCX $101 \mathrm{~kb})$

\section{Abbreviations}

ANRESIS: Swiss antimicrobial resistance surveillance network; CLSI: Clinical and laboratory standards institute; CPE: Carbapenemase-producing Enterobacteriacae; CR: Carbapenem-resistance; ECDC: European centre for disease prevention and control; ESBL: Extended-spectrum $\beta$-lactamase; ESCR: Extended-spectrum cephalosporin resistant; EUCAST: European committee on antimicrobial susceptibility testing; FOPH: Federal office of public health; GEE: Generalized estimating equation; GRE: Glycopeptide-resistant enterococci; IQR: Interquartile range; LTCF: Long-term care facility; MRSA: Methicillin-resistant Staphylococcus aureus; NH: Nursing home; OR: Odds ratio

\section{Funding}

The study has been funded by the Swiss Federal Office of Public Health (disposition number 17.008726).

\section{Availability of data and materials}

The datasets generated during and/or analysed during the current study are not publicly available but are available from the corresponding author on reasonable request. 


\section{Authors' contributions}

The study was conceptualized by PK, MS and AK with the help of all coauthors. ANRESIS data were provided by AK. PK performed the data analysis. PK and AK drafted a first version of the manuscript. All authors contributed to the final version of the manuscript.

\section{Ethics approval and consent to participate}

Because ANRESIS contains routinely collected anonymized surveillance data, ethical consent was not required according to the Swiss law for research on human beings.

\section{Consent for publication}

Not applicable.

\section{Competing interests}

The authors declare that they have no competing interests.

\section{Publisher's Note}

Springer Nature remains neutral with regard to jurisdictional claims in published maps and institutional affiliations.

\section{Author details}

'Division of Infectious Diseases and Hospital Epidemiology, Kantonsspital St. Gallen, St. Gallen, Switzerland. ${ }^{2}$ Clinical Microbiology Division, University Hospital Basel, Basel, Switzerland. ${ }^{3}$ Applied Microbiology Research, Department of Biomedicine, University of Basel, Basel, Switzerland. ${ }^{4}$ Servizio di prevenzione delle infezioni e medicina del personale, Ente Ospedaliero Cantonale, Ticino, Switzerland. ${ }^{5}$ Division of Infectious Diseases and Infection Control Program, Geneva University Hospitals and Faculty of Medicine, Geneva, Switzerland. ${ }^{6}$ Unité cantonale hygiène, prévention et contrôle de I'infection, Canton of Vaud, Switzerland. ${ }^{7}$ Division of Infectious Diseases and Hospital Epidemiology, Children's Hospital of Eastern Switzerland, St. Gallen, Switzerland. ${ }^{8}$ Division of Infectious Diseases and Hospital Epidemiology, University and University Hospital Zurich, Zurich, Switzerland. ${ }^{9}$ Institute for Infectious Diseases, University Bern, Bern, Switzerland. ${ }^{10}$ Swiss Centre for Antibiotic resistance (ANRESIS), Bern, Switzerland.

Received: 9 May 2018 Accepted: 6 July 2018

Published online: 20 July 2018

\section{References}

1. Lin MY, Lyles-Banks RD, Lolans K, Hines DW, Spear JB, Petrak R, et al. The importance of long-term acute care hospitals in the regional epidemiology of Klebsiella pneumoniae carbapenemase-producing Enterobacteriaceae. Clin Infect Dis. 2013;57(9):1246-52.

2. Strausbaugh LJ, Crossley KB, Nurse BA, Thrupp LD. Antimicrobial resistance in long-term-care facilities. Infect Control Hosp Epidemiol. 1996;17(2):129-40.

3. Wiener J, Quinn JP, Bradford PA, Goering RV, Nathan C, Bush K, et al. Multiple antibiotic-resistant Klebsiella and Escherichia coli in nursing homes. JAMA. 1999:281(6):517-23.

4. Giufre M, Ricchizzi E, Accogli M, Barbanti F, Monaco M, Pimentel de Araujo $F$, et al. Colonization by multidrug-resistant organisms in long-term care facilities in Italy: a point-prevalence study. Clin Microbiol Infect. 2017;

5. Aschbacher R, Pagani E, Confalonieri M, Farina C, Fazii P, Luzzaro F, et al. Review on colonization of residents and staff in Italian long-term care facilities by multidrug-resistant bacteria compared with other European countries. Antimicrob Resist Infect Control. 2016:5:33.

6. Harbarth S, Sax H, Fankhauser-Rodriguez C, Schrenzel J, Agostinho A, Pitte D. Evaluating the probability of previously unknown carriage of MRSA at hospital admission. Am J Med. 2006;119(3):275.e15-23.

7. Tacconelli E, Karchmer AW, Yokoe D, D'Agata EM. Preventing the influx of vancomycin-resistant enterococci into health care institutions, by use of a simple validated prediction rule. Clin Infect Dis. 2004;39(7):964-70.

8. Ben-David D, Masarwa S, Navon-Venezia S, Mishali H, Fridental I, Rubinovitch $B$, et al. Carbapenem-resistant Klebsiella pneumoniae in post-acute-care facilities in Israel. Infect Control Hosp Epidemiol. 2011:32(9):845-53.

9. Leitner E, Zechner E, Ullrich E, Zarfel G, Luxner J, Pux C, et al. Low prevalence of colonization with multidrug-resistant gram-negative bacteria in long-term care facilities in Graz. Austria Am J Infect Control. 2017;

10. Hequet D, Rousson V, Blanc DS, Bula C, Qalla-Widmer L, Masserey E, et al. Universal screening and decolonization for control of MRSA in nursing homes: follow-up of a cluster randomized controlled trial. J Hosp Infect. 2017:96(1):69-71.

11. Blanc DS, Pittet D, Ruef C, Widmer AF, Muhlemann K, Petignat C, et al Epidemiology of methicillin-resistant Staphylococcus aureus: results of a nation-wide survey in Switzerland. Swiss Med Wkly. 2002;132(17-18):223-9.

12. Gagnon G, Attinger M, Nahimana I, Tessemo C, Petignat C. Surveillance des infections urinaires à entérobactéries productrices de beta lactamase à spectre élargi en EMS. Joint Annual Meeting, Swiss Society for Infectious Diseases, Poster 92, Montreux 2016. https://kongress.imk.ch/download/ sginf2016_attachments/FileBaseDoc/IMSDKG16_Abstractbook.pdf. Last Accessed 28 Mar 2018.

13. Bellini C, Petignat C, Masserey E, Bula C, Burnand B, Rousson V, et al. Universal screening and decolonization for control of MRSA in nursing homes: a cluster randomized controlled study. Infect Control Hosp Epidemiol 2015:36(4):401-408.

14. Olearo F, Albrich WC, Vernaz N, Harbarth S, Kronenberg A. Swiss Centre for antibiotic resistance a. Staphylococcus aureus and methicillin resistance in Switzerland: regional differences and trends from 2004 to 2014. Swiss Med Wkly. 2016;146:w14339.

15. Kronenberg A, Hilty M, Endimiani A, Muhlemann K. Temporal trends of extended-spectrum cephalosporin-resistant Escherichia coli and Klebsiella pneumoniae isolates in in- and outpatients in Switzerland, 2004 to 2011. Euro Surveill. 2013;18(21):23.

16. Schweizerisches Zentrum für Antibiotikaresistenzen. Institut für Infektionskrankheiten Universität Bern, Switzerland. http://www.anresis.ch/. Last Accessed 28 Mar 2018.

17. Clinical and Laboratory Standards Institute (CLSI). Wayne: CLSI. Available from: http://www.clsi.org. Last accessed 28 Mar 2018.

18. European Committee on Antimicrobial Susceptibility Testing (EUCAST). Breakpoint tables for interpretation of MICs and zone diameters. Version 7.1 valid from 2013-03-10. Available from: http://www.eucast.org/fileadmin/src/ media/PDFs/EUCAST_files/Breakpoint_tables/v_7.1_Breakpoint_Tables.pdf. Last Accessed 28 Mar 2018

19. UK NEQAS, International Quality Expertise. Available from: www.ukneqas.org. uk. Last Accessed 28 Mar 2018.

20. Universität Zürich. Institut für Medizinische Mikrobiologie. Available from: http://www.imm.uzh.ch/de/services/qc.html. Last Accessed 28 Mar 2018.

21. Bundesamt für Gesundheit BAG. Gesamtschweizerische und kantonale Kennzahlen 2016. Available at: http://www.bag-anw.admin.ch/2016_taglab/ 2016 somed/data/download/2016_Kantonale_Kennzahlen_de.pdf?v= 1512121715. Last Accessed 28 Mar 2018.

22. Bundesamt für Gesundheit BAG. Kennzahlen der Schweizer Pflegeheime 2016. Available at: http://www.bag-anw.admin.ch/2016_taglab/2016_ somed/data/download/2016_Kennzahlen_alle_de.pdf?v=1512121719. Last Accessed 28 Mar 2018

23. World Health Organisation: Central Asian and Eastern European Surveillance of Antimicrobial Resistance. Annu Rep 2017. Available at: http://www.euro. who.int/_data/assets/pdf_file/0005/354434/WHO_CAESAR_AnnualReport 2017.pdf?ua=1. Last Accessed 28 Mar 2018

24. Pilmis B, Cattoir V, Lecointe D, Limelette A, Grall I, Mizrahi A, et al. Carriage of ESBL-producing Enterobacteriaceae in French hospitals: the PORTABLSE study. J Hosp Infect 2017.

25. Hogardt M, Proba P, Mischler D, Cuny C, Kempf VA, Heudorf U. Current prevalence of multidrug-resistant organisms in long-term care facilities in the Rhine-main district, Germany, 2013. Euro Surveill. 2015:20(26)

26. Zollner-Schwetz I, Zechner E, Ullrich E, Luxner J, Pux C, Pichler G, et al. Colonization of long term care facility patients with MDR-gram-negatives during an Acinetobacter baumannii outbreak. Antimicrob Resist Infect Control 2017;6:49

27. Ben-Ami R, Rodriguez-Bano J, Arslan H, Pitout JD, Quentin C, Calbo ES, et al. A multinational survey of risk factors for infection with extended-spectrum beta-lactamase-producing enterobacteriaceae in nonhospitalized patients. Clin Infect Dis. 2009;49(5):682-90

28. Jans B, Schoevaerdts D, Huang TD, Berhin C, Latour K, Bogaerts $P$, et al. Epidemiology of multidrug-resistant microorganisms among nursing home residents in Belgium. PLoS One. 2013;8(5):e64908.

29. Nakai H, Hagihara M, Kato H, Hirai J, Nishiyama N, Koizumi Y, et al. Prevalence and risk factors of infections caused by extended-spectrum beta-lactamase (ESBL)-producing Enterobacteriaceae. J Infect Chemother. 2016;22(5):319-26.

30. Pena C, Gudiol C, Tubau F, Saballs M, Pujol M, Dominguez MA, et al. Riskfactors for acquisition of extended-spectrum beta-lactamase-producing 
Escherichia coli among hospitalised patients. Clin Microbiol Infect. 2006; 12(3):279-84.

31. Rodriguez-Bano J, Alcala JC, Cisneros JM, Grill F, Oliver A, Horcajada JP, et al. Community infections caused by extended-spectrum beta-lactamaseproducing Escherichia coli. Arch Intern Med. 2008;168(17):1897-902.

32. Pitout JD, Hanson ND, Church DL, Laupland KB. Population-based laboratory surveillance for Escherichia coli-producing extended-spectrum betalactamases: importance of community isolates with blaCTX-M genes. Clin Infect Dis. 2004;38(12):1736-41.

33. Rooney PJ, O'Leary MC, Loughrey AC, McCalmont M, Smyth B, Donaghy P, et al. Nursing homes as a reservoir of extended-spectrum beta-lactamase (ESBL)-producing ciprofloxacin-resistant Escherichia coli. J Antimicrob Chemother. 2009;64(3):635-41.

34. Han JH, Garrigan C, Johnston B, Nachamkin I, Clabots C, Bilker WB, et al. Epidemiology and characteristics of Escherichia coli sequence type 131 (ST131) from long-term care facility residents colonized intestinally with fluoroquinolone-resistant Escherichia coli. Diagn Microbiol Infect Dis. 2017: 87(3):275-80.

35. Burgess MJ, Johnson JR, Porter SB, Johnston B, Clabots C, Lahr BD, et al. Long-term care facilities are reservoirs for antimicrobial-resistant sequence type 131 Escherichia coli. Open Forum Infect Dis 2015;2(1):ofv011.

36. Guidelines of the Swiss Society for Infectious Diseases, Urinary Tract Infections, May 2014 [in German]. Available at: http://www.sginf.ch/files/ behandlung_von_unkomplizierten_harnwegsinfektionen.pdf. Last Accessed 28 Mar 2018.

37. Voor In't Holt AF, Severin JA, Lesaffre EM, Vos MC. A systematic review and meta-analyses show that carbapenem use and medical devices are the leading risk factors for carbapenem-resistant Pseudomonas aeruginosa. Antimicrob Agents Chemother 2014;58(5):2626-2637.

38. Wolfensberger A, Sax H, Weber R, Zbinden R, Kuster SP, Hombach M. Change of antibiotic susceptibility testing guidelines from CLSI to EUCAST: influence on cumulative hospital antibiograms. PLoS One. 2013;8(11):e79130.

39. ANRESIS. Swiss Antibiotic Resistance Report 2016. Available at: http://anresis. ch/files/pdf/BAG_Swiss_Antibiotic_Resistance_Report_2016_WEB.pdf. Last Accessed 28 Mar 2018

40. ECDC Surveillance Report. Surveillance of Antimicrobial Resistance in Europe Available from: https:/lecdc.europa.eu/sites/portal/files/documents/AMRsurveillance-Europe-2016.pdf. Last Accessed 28 Mar 2018.

Ready to submit your research? Choose BMC and benefit from:

- fast, convenient online submission

- thorough peer review by experienced researchers in your field

- rapid publication on acceptance

- support for research data, including large and complex data types

- gold Open Access which fosters wider collaboration and increased citations

- maximum visibility for your research: over $100 \mathrm{M}$ website views per year

At $\mathrm{BMC}$, research is always in progress.

Learn more biomedcentral.com/submissions 